\title{
THE PERSPECTIVES OF USE OF HIGH OLEIC SUNFLOWER FOR OLEOCHEMISTRY AND ENERGY RAWS
}

\author{
Vannozzi, G.P. ${ }^{*}$ \\ Dipartimento di Scienze Agrarie et Ambientali, \\ Via delle Scienze 208, 33100 Udine, Italy
}

Received: September 10, 2005 Accepted: March 25, 2006

SUMMARY

The high oleic sunflower has a high potential for industrials use (oleochemistry and biodiesel). A sustainable development of agriculture can be achieved through the production of high oleic sunflower oil for use in green chemistry. In such a way will it be possible to create secure jobs in agriculture as well as in new industries, especially in rural communities.

Key words: biodiesel, high oleic, green chemistry, sunflower

\section{INTRODUCTION}

Renewable raw materials include agricultural raw materials such as oil from oilseed crops, starch from cereals and potatoes, sugar from sugar beet, and cellulose from straw and wood. They can be converted into polymers, lubricants, solvents, surfactants and specialty chemicals through physical, chemical and biochemical processes.

Major market opportunities and potential applications for RRM fall into four main areas: chemicals, specialty chemicals, industrial fibers and industrial oils.

The main drives for industry towards a greater reliance on RRM are:

- Cost. Although the price of mineral oil remains low, there are certain special applications where the 'cost of use' of RRM is competitive even today (Table 1).

- Functionality. Plant-derived materials offer an inherently natural range of functionalities, from biodegradability, which is of use in the disposal of certain packaging materials, to high value applications, tailor-made for special uses such as the controlled release of drugs from starch-based capsules.

- Responsible Care. Industry increasingly wishes to demonstrate its responsi-

* Corresponding author, Phone: +39 0432 558620, +39349 8313394;

e-mail: vannozzi@uniud.it 
bility concerning health and environmental issues.

- Sustainability. Plant-derived products can reduce $\mathrm{CO}_{2}$ emissions, i.e., they are part of the closed carbon cycle and their production, use and disposal are consistent with the goal of sustainability.

Table 1: Cost of plant/crop-based raw materials with a barrel oil cost of $40 \$$

\begin{tabular}{lcccc}
\hline \multirow{1}{*}{ Product } & Production & Conventional Cost & Plant Derived Cost & Plant Derived \\
\cline { 2 - 5 } & Million tons & $\$ / \mathrm{lb}$ & $\$ / \mathrm{lb}$ & $\%$ \\
\hline Furfural & 0.3 & 0.75 & 0.78 & 97.0 \\
Adhesives & 5.0 & 1.65 & 1.40 & 40.0 \\
Fatty Acids & 2.5 & 0.46 & 0.33 & 40.0 \\
Sufactans & 3.5 & 0.45 & 0.45 & 35.0 \\
Acetc Acid & 2.3 & 0.33 & 0.35 & 17.5 \\
Plasticizers & 0.8 & 1.50 & 2.50 & 15.0 \\
Carbon Black & 1.5 & 0.50 & 0.45 & 12.0 \\
Detergents & 12.6 & 1.10 & 1.75 & 11.0 \\
Pigments & 15.5 & 2.00 & 5.80 & 6.0 \\
Dyes & 4.5 & 12.00 & 21.00 & 6.0 \\
Wall Paints & 7.8 & 0.5 & 1.20 & 3.5 \\
Inks & 3.5 & 2.00 & 2.50 & 3.5 \\
Special Paints & 2.4 & 0.80 & 1.75 & 2.0 \\
Plastics & 30.0 & 0.50 & 2.00 & 1.8 \\
\hline
\end{tabular}

Benefits for the economy arising from a wider use of RRM will include:

- Strengthening of industry's competitive position through the development and licensing (to third countries) of sustainable technologies in the production, processing and use of crop-derived raw materials.

- Stimulation of an increased use of advanced technologies to improve the efficiency of crop production and adapt plant products to meet industry needs through, for example, improved biosynthetic pathways.

- Creation of secure jobs in agriculture as well as in new industries, especially in rural communities.

- Utilization of land for non-food production, opening new markets, would make efficient use of surplus land for food and feed production. The current area available in EU is 6 million hectares and this could double within 10 years.

- Improvement in health of many industrial workers through reduced contact with harmful substances.

- Improved soil and water quality through a reduction in toxic effluents from manufacturing processes.

- Reduced pressure on landfill sites through special waste management systems such as the composting of bio-degradable materials.

- Increased use of RRM would lead to a reduction in greenhouse gas emissions.

- Introduction of alternative, non-food crops into agriculture would lead to an increase in bio-diversity on farms.

- Benefits related to the security of supply of raw materials and biodegradability of products. 
The vision of the EU is the increase of the use of RRM as is indicated in Figure 1.

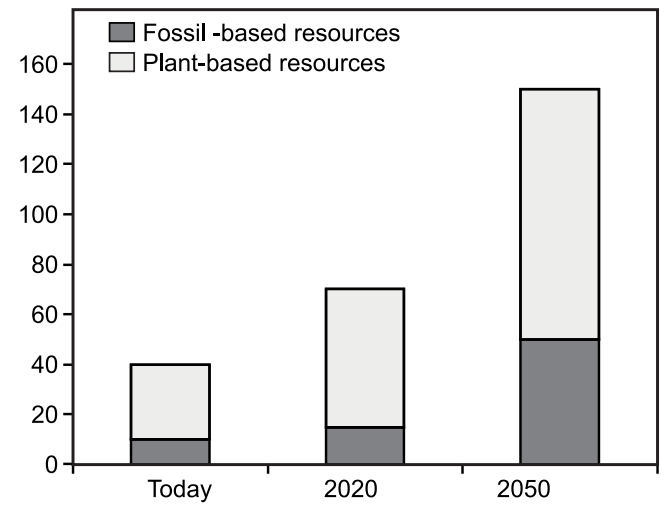

Figure 1: Vision 2050 - Plant-fossil utilization balance

\section{The oilseed in the world}

As indicated in Figures 2 and 3, the world consumption of oils and fats 2001/ 2002 has changed from that in 1991/1992.

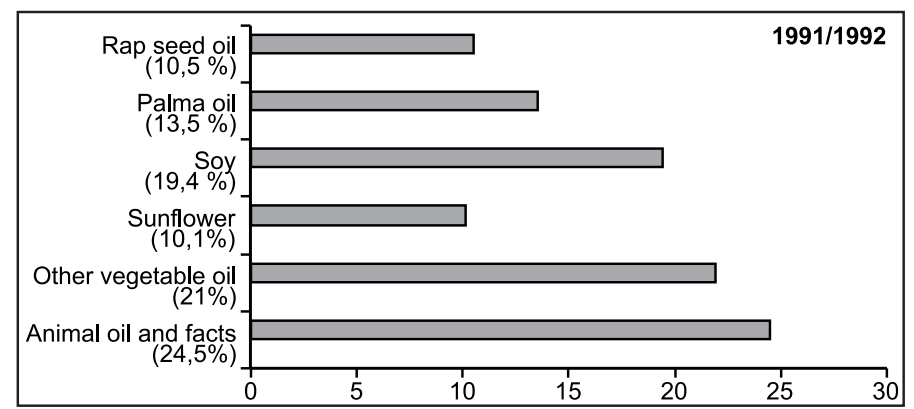

Figure 2: World consumption of oils and fats in 1991/1992

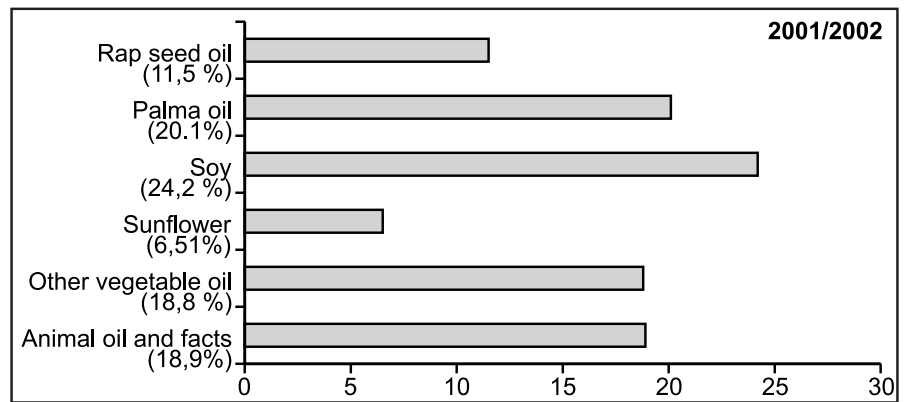

Figure 3: World consumption of oils and fats in 2001/2002

From 1991/1992 to 2001/2002 in the world, the use of animal oils and fats decreased and the use of soy and palm oil increased. 
In the some time the population of the world increased as well as the income (Figure 4).
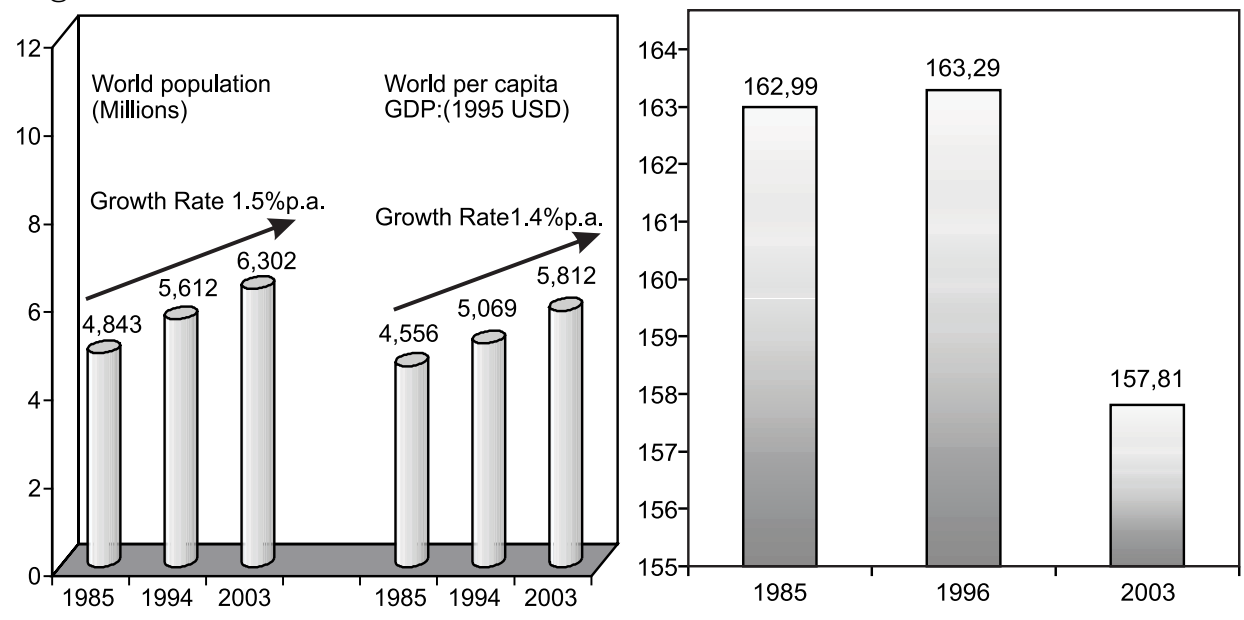

Figure 4: World population and world per capita income during 1985-2003

Figure 5: World food grain per capita consumption: ( $\mathrm{kg}$, rice and wheat)

The consumption of cereals decreased as the income increased, as show in Figure 5. At the some time, the consumption of proteins and vegetable oils increased (Figure 6). Figure 7 shows the relations between per capita income and per capita vegetable oil consumption.

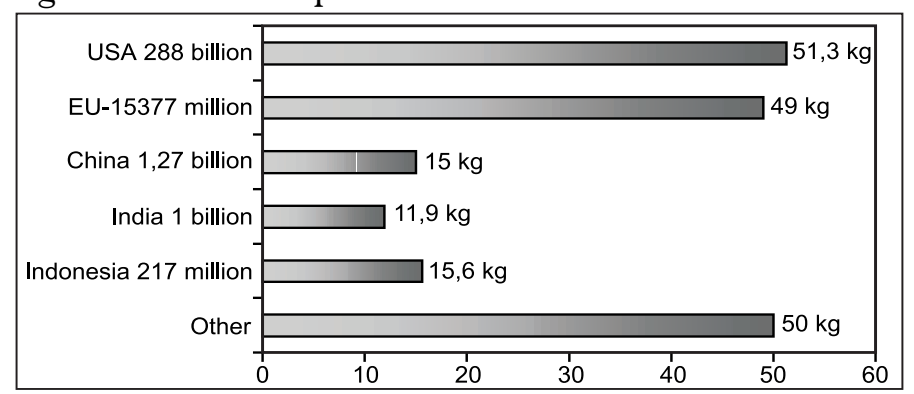

Figure 6: World per capita meat/vegetable oil consumption ( $\mathrm{kg}$ )

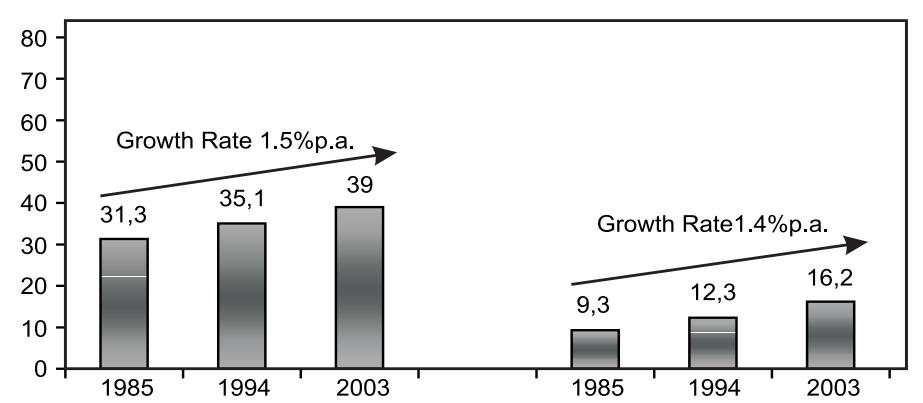

Figure 7: World per capita income and per capita vegetable oil consumption 
The per capita vegetable oils consumption and world population are indicated in Figure 8 and Table 2.

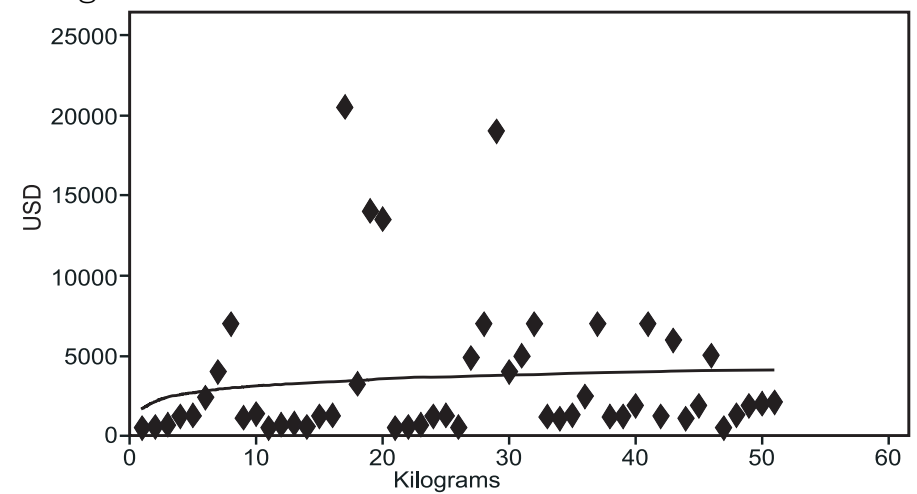

Figure 8: World population and per capita vegetable oils consumption in 2002 (total world production 6.23 billion, world average $19.35 \mathrm{~kg}$, Australia $32 \mathrm{~kg}$ )

Table 2: World population and consumption in 1990-2010

\begin{tabular}{lccccc}
\hline Year & 1990 & 1995 & 2002 & 2006 & 2010 \\
\hline Population (billions) & 5.300 & 5.670 & 6.23 & 6.280 & 6.649 \\
Consumption (kg/capita) & 16.29 & 16.34 & 19.36 & 19.95 & 20.90 \\
\hline
\end{tabular}

The vegetable oils consumption has increased dramatically in the last decade in China and India and the trend will continue due to the economic development of these two countries.
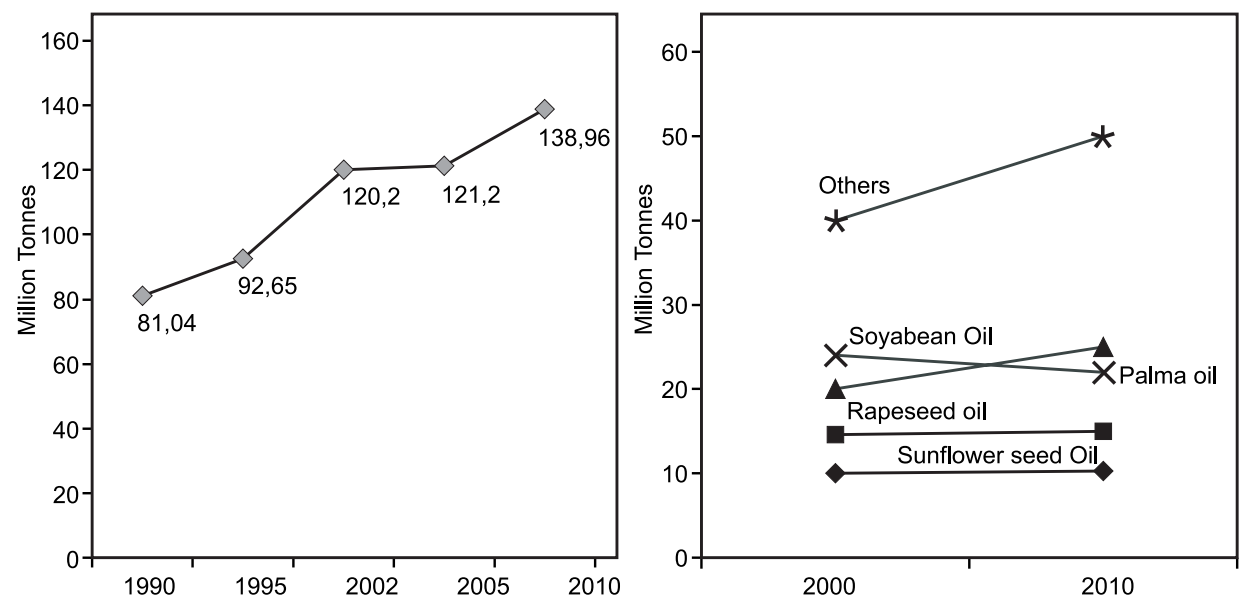

Figure 9: Actual \& projected consumptions Figure 10: Future production of fats \& oils of oil \& fats over years $1990-2010$

The projected consumptions of oils \& fats over years 1990-2010 (Figure 9) indicate an increase of 20 million tons in the oils consumption and an oil per capita consumption from 19.95 to $20.90 \mathrm{~kg}$ from 2005 to 2010 . 
Figure 10 indicates the estimated production of oils and fats in 2010. Sunflower, rapeseed and soy oils will have a little increase against an increase of 10 million tons for palm oil.

\section{Sunflower oil industrials uses}

The first European record of using sunflower seed as a source of oil is the English patent no. 408, granted to Arthur Bunyan in 1716, for inventing:

"How from a certain English seed might be expressed a good sweet oil of great use to all persons concerned in the woolen manufacture, painters, leather dressers etc....such oil so to be made is to be expressed from the seed of the flowers commonly called \& known by the name of sunflowers of all sorts, both double \& single".

Two implications are evident in this patent. First, the oil was intended for industrial rather than edible use and second, extensive variation in the plant type existed.

Of the approx. 120 million tons of fats and oils which were produced worldwide in 2004, by far the largest share was used in human foodstuffs. Of that amount, 25 million tons were available for oleochemistry. The composition of fatty acids contained in the oils determines their further use. Special attention must be given to coconut and palm kernel oils because of their high share of fatty acids with a shortor medium-chain length (mainly C12 and C14). For example, these are particularly suitable for further processing to surfactants. Palm, soybean, rapeseed and sunflower oils contain mainly long-chain fatty acids $(\mathrm{C} 18)$ and are used as raw materials for polymer applications and lubricants.

In recent years the percentage of vegetable oils going into no-food uses has increased (Figure 11).

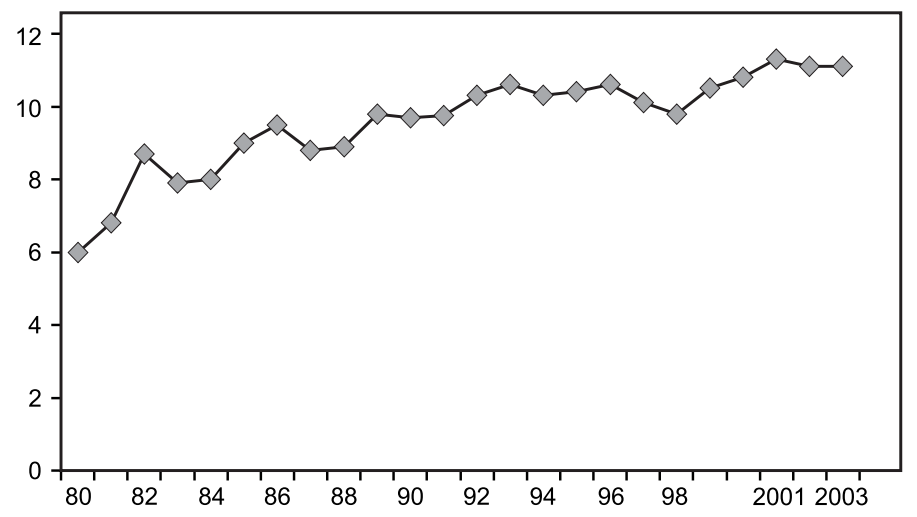

Figure 11: Percentage of vegetable oils going into no-food uses

The general criteria for oil selection/industrial use are as follows:

- Total costs: purchase, maintenance, handling, storage, disposal...

- Performance: specific parameters/properties for each application, e.g., lubri- 
cants: friction reduction, anti wear, heat transfer...

- Lifetime: shelf life, consumption, extension, oxidation behavior...

- Raw material supply: availability, security, quality, competitiveness...

- Product Safety: toxicity, health hazards, flashpoint...

- Environmental aspects: biodegradability, toxicity, climate change

- Disposal: recovery/waste management, legal affairs..

- Innovation aspects: EINECS, patents, exclusivity...

\section{Biodiesel}

The concept of using vegetable oil as a fuel is not new. Dr. Rudolf Diesel first developed the diesel engine in 1895 with the full intention of running it on a variety of fuels, including vegetable oil. Diesel demonstrated his engine at the World Exhibition in Paris in 1900 using peanut oil as fuel. In 1911 he stated: "The diesel engine can be fed with vegetable oils and would help considerably in the development of agriculture of the countries which use it." In 1912, Diesel said: "The use of vegetable oils for engine fuels may seem insignificant today. But such oils may become in course of time as important as petroleum and the coal tar products of the present time." Since Diesel's time, the design of the diesel engine has been modified so it can run on the cheapest fuel available: petroleum "diesel" fuel.

Chemically, biodiesel is a mono alkyl ester of long chain fatty acid. Biodiesel is a methyl ester produced by a chemical process (transesterification) that reacts virgin vegetable oils (soy, corn, canola, cottonseed, peanut, sunflower, rapeseed) or used frying oils (yellow grease) or animal fats (beef tallow, poultry fat, pork lard) with methanol and a potassium hydroxide catalyst. The oil's triglycerides react to form esters and glycerol, a byproduct of biodiesel process.

In organic chemistry, transesterification is the process of exchanging the alkoxy group of an ester compound by another alcohol. These reactions are often catalyzed by the addition of an acid or base.

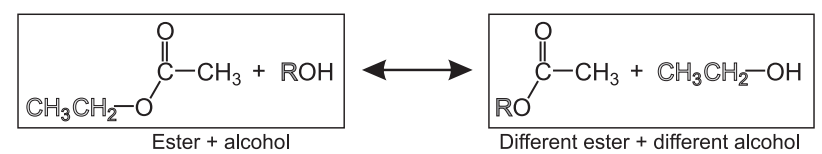

Acids can catalyze the reaction by donating an electron to the alkoxy group, thus making it more reactive, while bases can catalyze the reaction by removing an electron from the alcohol, thus making it more reactive.

One of the first uses of transesterified vegetable oil (biodisel) was powering heavy duty vehicles in South Africa before World War II. The name "biodiesel" has been given to transesterified vegetable oil to describe its use as a diesel fuel. It was patented in the USA in the 1940s by the Colgate (and other) scientists, though biolipid transesterification had been discovered much earlier. In the 1940s researchers were looking for a method to produce glycerin more readily, in order to produce explosives for World War II. Many of the methods used today by producers and home brewers have their origin in the original 1940s research. 


\section{The production of biodiesel}

There are three basic routes to ester production from oils and fats:

- Base-catalyzed transesterification of oil with alcohol.

- Direct acid-catalyzed esterification of oil with methanol.

- Conversion of oil to fatty acids, and then to alkyl esters with acid catalysis.

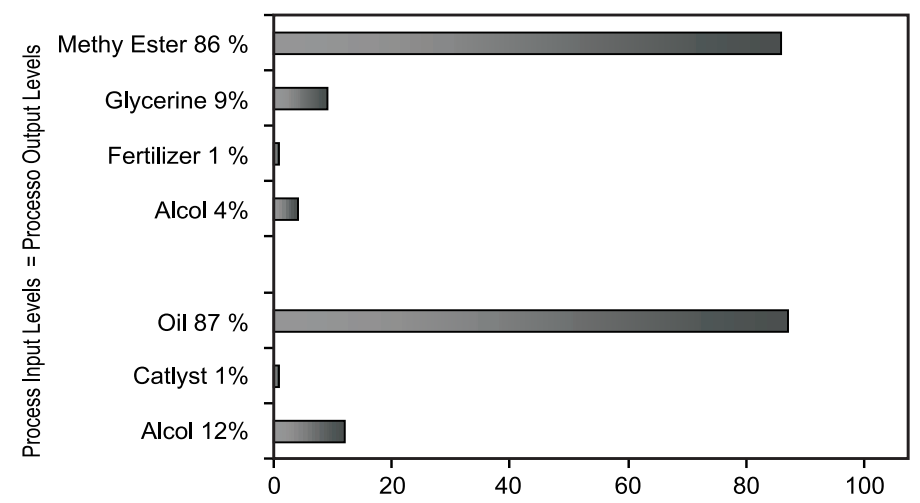

Figure 12: Biodiesel production process by means of oil esterification

Today, alkyl esters are predominantly produced by the base-catalyzed reaction. It is most economic for several reasons:

- Low temperature (150 F) and pressure (20 psi) processing.

- High conversion (98\%) with minimal side reactions and reaction time.

- Direct conversion to methyl ester with no intermediate steps.

- Exotic construction materials are not necessary.

The general process is depicted below.

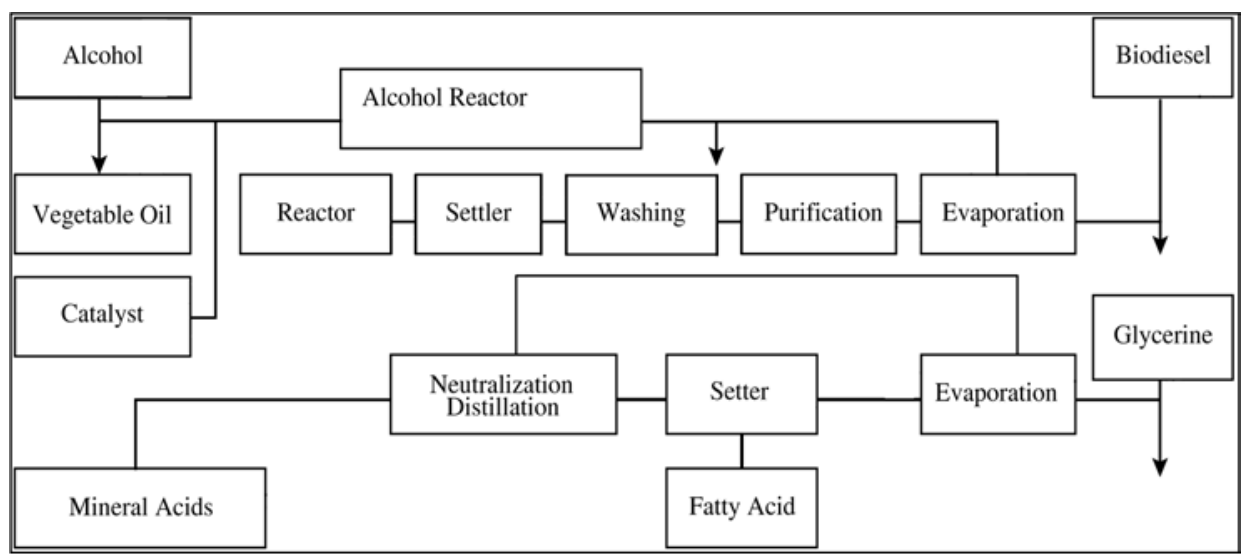

Figure 13: Scheme of biodiesel production process

A fat or oil is reacted with an alcohol, like methanol, in the presence of a catalyst to produce glycerin and methyl esters or biodiesel. The methanol is charged in 
excess to assist in quick conversion and recovered for reuse. The catalyst is usually sodium or potassium hydroxide which has been mixed with methanol prior to the reaction.

Europe has been developing their biodiesel market for over 20 years. Much work has been done by the institutions and associations of vehicle/engine manufacturers. Around 2 million diesel vehicles in Europe are now certified to run on biodiesel.

The best standard in Europe is the German E-Din 51606 standard. The standards within Europe are usually feedstock (the types of oil/alcohol used) specific.

\section{Main advantages of biodiesel}

As far as environmental issues are at stake, biodiesel has been demonstrated to have significant benefits in terms of decreased greenhouse gases emissions. Various studies concluded that the use of $1 \mathrm{~kg}$ of biodiesel leads to the reduction of some $3 \mathrm{~kg}$ of $\mathrm{CO}_{2}$. As such, the increased use of biodiesel represents a significant tool for the EU to meet its $\mathrm{CO}_{2}$ emission reduction target of Kyoto.

For each unit of fossil energy used to produce biodiesel, 3.37 units of biodiesel energy are created if soybean oil is used, 4.7 units if rapeseed oil is used and 5.5 units if sunflower oil is used.

Additionally, biodiesel is extremely low in sulphur and it has fast biodegradability. Recently, two studies carried out by Shell and Concawe (the Oil Companies European Organization for Environment, Health and Safety) have acknowledged the environmental advantages of biodiesel.

Biodiesel also has important benefits in terms of health. More specifically, it has a strong impact on the reduction of particulate matters emissions. According to a US Environment Protection Agency study the use of biodiesel instead of petroleum-based diesel could offer a 93.6\% reduction in cancer risks from particulate matter emission exposure. More recently, the French Institute for Health Monitoring (INVS) has issued a very interesting study showing that air pollution kills nearly 3,000 people per year in nine of France's largest cities. This is the first time the deaths linked to air pollution are precisely quantified: biodiesel could help to considerably reduce these figures.

The potential in terms of rural development is also very important. Rural development is now considered by EU authorities as the "second pillar" of the Common Agricultural Policy (CAP). The production of biodiesel can help diversify the outlets of the EU agricultural production and encourage the planting of oilseed crops which are less demanding in terms of pesticides and fertilizers (rapeseed is considered by agronomists as a sort of weed).

Also, an increased production of biodiesel could have an important impact in terms of new employment opportunities, especially in rural areas. A recent study of the German IFO institute has calculated that up to $80 \%$ of the detaxation granted to biodiesel in Germany is covered by internalizing macroeconomic benefits. This IFO 
study, titled "Total economic assessment of oil seed rape cultivation for biodiesel production", also comes to the conclusion that the growing biodiesel industry secures some 19,000 jobs in agriculture, processing of raw materials and marketing of biodiesel.

Finally, the development of biodiesel would contribute to the diversification of energy supply. In the case of Europe it could reduce the EU dependence on oil imports. The present geographic distribution of oil resources is very unfavorable: $78 \%$ of petroleum reserves are located in OPEC areas and this percentage is increasing. Independence of energy supply will become a central issue in Europe in next decade: the reserves of petroleum and natural gas in the North Sea region are quite limited. With the current production intensity, oil reserves in that region will be exhausted in 10 to 15 years, while natural gas will last for 25 years.

Europe is the main world producer of biodiesel. Production is obviously concentrated in those countries where detaxation is provided. The main producers are Germany and France and Italy, as indicated in Tables 3 and 4. The European Union biodiesel production in 2004 is near to the figure of 2 million tons.

Table 3: The main world producers of biodiesel in 2003

\begin{tabular}{lc}
\hline \multirow{2}{*}{ Country } & Production \\
\cline { 2 - 2 } & in 000 tonnes* \\
\hline Germany & 715 \\
France & 357 \\
Italy & 273 \\
Austria & 32 \\
Spain & 6 \\
Denmark & 41 \\
Unied Kingdom & 9 \\
Sweden & 1 \\
\hline Total & 1.434 \\
\hline
\end{tabular}

Table 4: The main world producers of biodiesel in 2004.

\begin{tabular}{lc}
\hline \multirow{2}{*}{ Country } & Production \\
\cline { 2 - 2 } & in 000 tonnes* \\
\hline Germany & 1088 \\
France & 502 \\
Italy & 419 \\
Austria & 100 \\
Spain & 70 \\
Denmark & 44 \\
Unied Kingdom & 15 \\
Sweden & 8 \\
\hline Total & 2246 \\
\hline
\end{tabular}

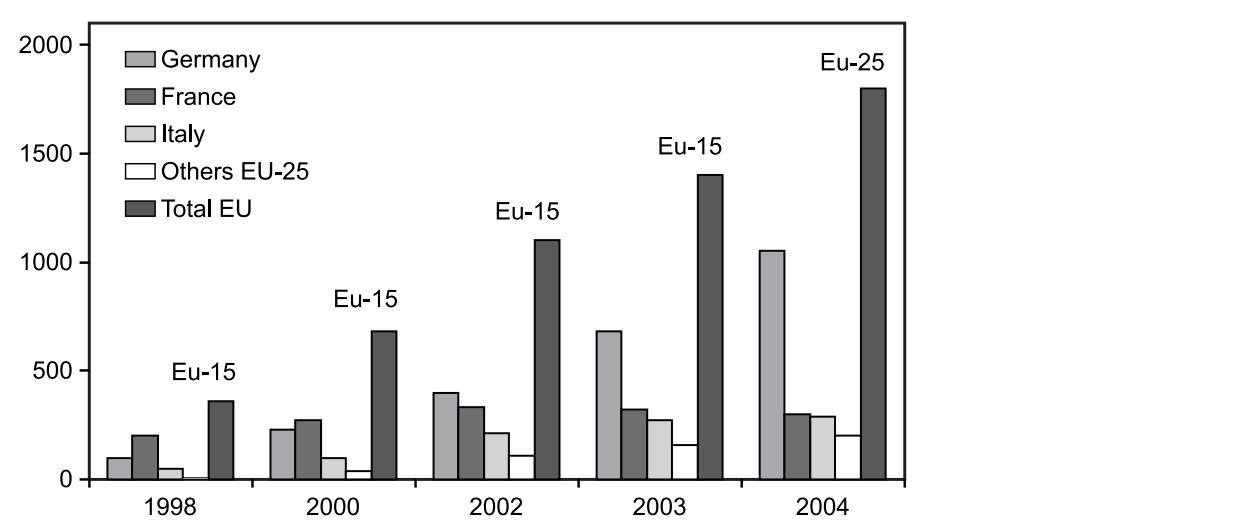

Figure 14:The European Union biodiesel production in 2004 


\section{Cost and price structure}

The economics of the biodiesel business can be explained by starting from its cost and price structure.

The cost of biodiesel mainly depends on the world prices of vegetable oils. However, the biodiesel business is a very specific one: it does not work on a well-defined margin like the vegetable oils crushing and refining sector: the biodiesel industry only uses vegetable oils as a raw material.

This point is essential since the price of biodiesel is also closely linked to the price of mineral oils and to the locally applied level of detaxation.

In this framework the level of the petroleum tax is a crucial factor. Biodiesel needs both to be granted a substantial detaxation and to be sold in a context of strong petroleum taxation in order to be competitive.

Processing costs also have some importance and represent 5 to $10 \%$ of overall costs. Such costs include processing chemicals (methanol and sodium sulfate), electricity and logistics. Small production units (under 5,000 tons per year) have sensibly higher costs in terms of chemicals and logistics and are not economically viable if a quality product is to be produced. The importance of processing costs should decrease together with the development of biodiesel production, because of scale economies and as a result of R\&D activities.

The biodiesel production cost in Italy, as indicated in Table 5, is 0.791 euros if rapeseed oil is utilized and 0.716 euros if sunflower oil is utilized.

Table 5: Biodiesel production cost in Italy

\begin{tabular}{lcccc}
\hline Italy & Seed amount $(\mathrm{Kg})^{*}$ & Agricultural Costs & Inustrial Cost & Totals Cost \\
\hline Rapeseeds oil (38-40\%) & 3.03 & 0.627 & 0.164 & 0.791 \\
Sunflower oil (42\%) & 2.26 & 0.552 & 0.164 & 0.716 \\
\hline
\end{tabular}

* Seed amount, in kg, which is necessary for production of one liter of biodisel

\section{Biodiesel and vegetable oils world product}

World production of oilseeds and palm oil is forecast to expand in 2004/05 to 379.1 and 29.84 million metric tons, respectively, up 12 and $3 \%$ from 2003/04. The question of where this increase will be consumed is not completely resolved, as world consumption for oilseeds is forecast to increase by $7 \%$, and palm oil consumption to increase by $3 \%$.

Biodiesel is one component of the increasing demand. This industry converts approximately one ton of vegetable oil or animal fat into one ton of biodiesel for use mostly in motor vehicles, as well as heating fuel and as an industrial solvent.

World interest in biodiesel production is expanding rapidly. Large-volume production occurs mainly in Europe, with production there now exceeding 1.4 million tons per year. However, projects and proposals are being announced in many countries with a wide variety of oil sources as the input. 
There is great potential for demand-pull to increase oilseed production if biodiesel production expands.

The current high world price for crude oil (light sweet crude for August delivery on the New York Mercantile Exchange settled at US\$ 58.00 on July 15, 2004) makes biodiesel production more attractive.

\section{The future of biodiesel}

\section{Europe}

The future development of biodesel in the EU is regulated by the Directive 2003/30/EU of 8 May 2003 and Directive 2003/96/EU of 27 October 2003. The European Union's (EU) Directorate for General Transport and Energy is advocating the implementation of a renewable fuel standard. It has drafted a proposed rule that would require each member state to use a minimum of $2 \%$ biofuels in their transportation fuels by 2005 and increase to $5.75 \%$ by 2010 . Each member state must approve the rule before it goes to the EU Council of Ministers and the EU Parliament for final approval. This is a process that could take several years.

In 2010, 15 million hectares will be grown for biofuels production, particularly EU will have to produce 14 billion liters of biodiesel $(9.7$ million/ha with rapeseed and sunflower) and 13 billion liters of bioethanol (5.1 million/ha of cereals and 0.6 millions/ha of sugarbeet).

The EU envisages to replace $8 \%$ of fossil fuels with biofuels in 2020 .

\section{USA}

In recent years research and development of bio-diesel has generated much interest in the U.S. transportation fuel market. Like other renewable energies such as ethanol, biodiesel utilizes agricultural feedstock such as vegetable oils and animal fats to produce a cleaner-burning fuel. Such feedstock includes soybean oil and other oil crops; byproducts from livestock slaughter and processing such as tallow, yellow grease, and lard; and waste frying oils and grease from the food service industry, etc. All of these fats and oils can be converted to bio-diesel to blend with or substitute for petroleum diesel.

Soybean diesel emerged as a potential alternative diesel fuel due to the large supply of domestic soybean production in the U.S., its well-developed oil crushing industry, and the largest soybean processing capacity of any country in the world. Low soybean prices in recent years also provided an incentive for U.S. producers to look for new markets and uses.

The USA vision is to replace $10 \%$ of fossil fuels with biofuels by 2020 .

\section{Lubricants}

At the end of the 1800s and for thousands of years before that time, vegetable oils and animal fats served as lubricants. The rise of petroleum in the early 1900s, 
with its low crude oil prices and extensive transportation infrastructure, gave an economic advantage to the petroleum-based lubricants, which quickly expanded to dominate the entire market.

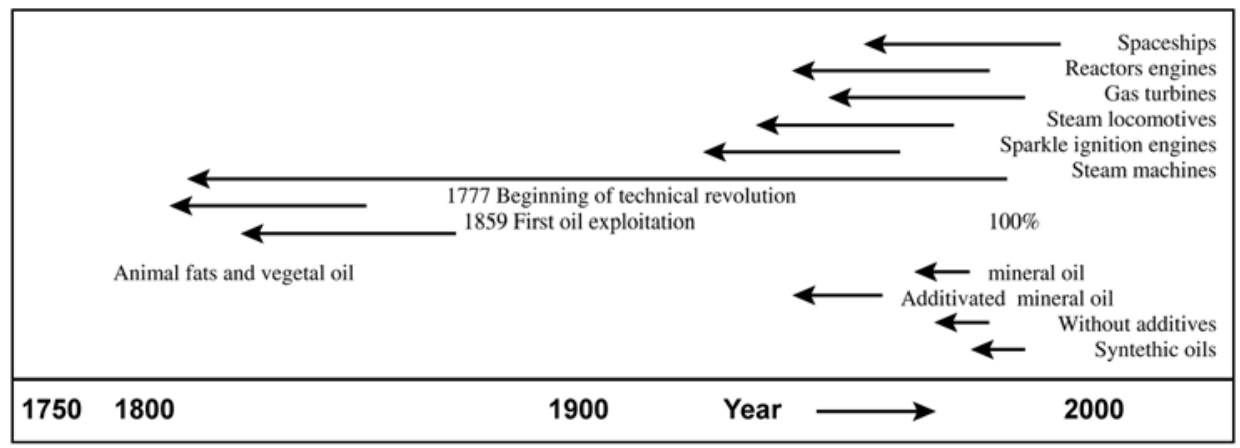

Figure 15: Evolution of lubricants application

Three main types of lubricants make up today's market. Petroleum oil-based lubricants (also called mineral oils) are derived from crude oil, and make up a vast majority of the lubricants sold today. Synthetic lubricants which have been synthesized from intermediate petrochemicals possess a range of high-performance attributes, often including biodegradability.

However, this trend is shifting. At the same time that the harmful effects of petroleum on environmental and human health have become more obvious, highperformance vegetable oil-based lubricants are being developed and marketed. While the overall lubricants market is predicted to remain fairly steady, Frost \& Sullivan forecasts that the biodegradable lubricants market will increase by $6.8 \%$ in 2000. Both plant-based and synthetic lubricants have the potential to capture this market.

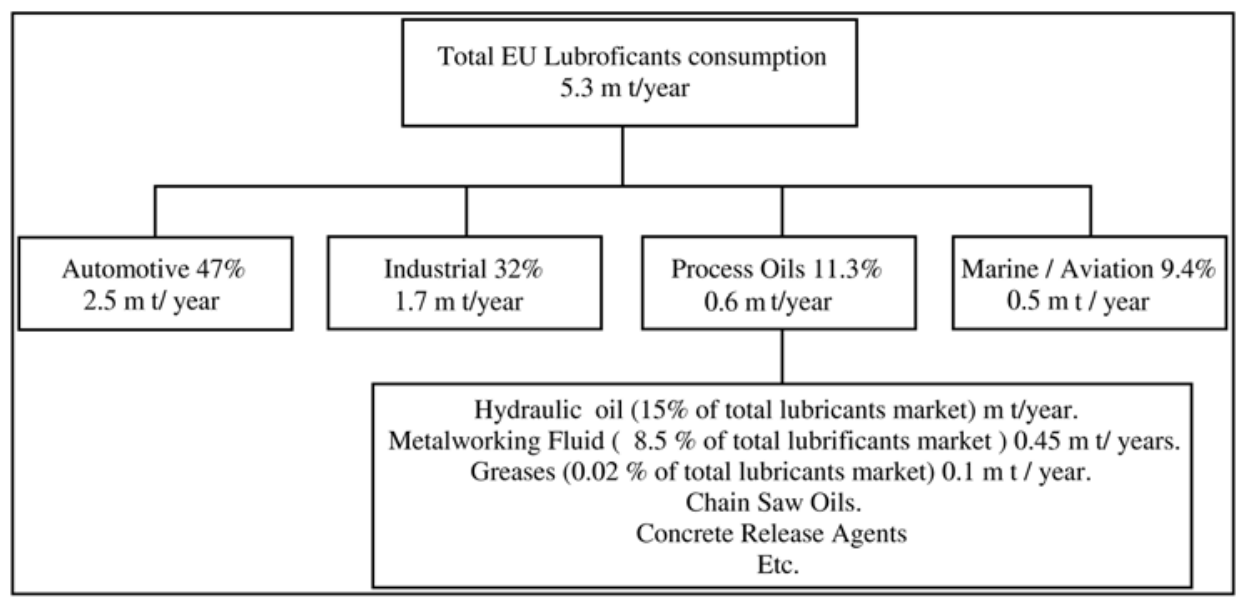

Figure 16: Scheme of world lubricant consumption 
The European lubricants market totals 5.3 million tons per annum and can be divided up as follows:

- 2.5 million tons of vehicle lubricants (47\%)

- 2.3 million tons of industrial lubricants (43\%)

- 0.5 million tons of marine and aviation lubricants (10\%)

- The total European market for drilling oils/muds amounts to 80,000 tpa.

Approximately $47 \%$ of lubricants and hydraulic fluids are lost into the environment. The so called "total loss" lubricants like off-shore drilling muds, concrete parting agents, chain bar oils, railroad flange oils, drip oils, and wire rope lubricants are completely lost into the environment. The loss rate for lubricants in twostroke engine oils is $34 \%$. Much of this loss goes directly into the marine environment. The loss rate for hydraulic fluid is $8 \%$.

Petroleum-based oils can contaminate ground water for up to 100 years, and as little as $0.1 \mathrm{ppm}$ of mineral oil can reduce the life span of shrimp by $20 \%$.

Vegetable oils have a number of inherent qualities that give them advantages over petroleum oils. Because vegetable oils are derived from a renewable resource, their use avoids the upstream pollution associated with petroleum extraction and refining. Unlike mineral oils, which can persist in the environment for years, vegetable oils are readily biodegradable. They are also low in toxicity and do not harm aquatic organisms and surrounding vegetation. These qualities are particularly important for lubricants used in environmentally sensitive areas such as marine ecosystems, and for those with a high potential of being lost to the surrounding environment.

From a worker safety perspective, plant-based lubricants are more attractive than their petroleum counterparts because of their relative low toxicity, high flash point and low volatile organic compound (VOC) emissions.

Vegetable oils offer a number of performance advantages as well. They have a naturally high viscosity index and thus do not thin as readily as petroleum oils in warm environments, allowing some lubricants a longer life. Vegetable oils possess superior natural lubricity-the ability to reduce friction-which results in less equipment wear.

In addition to their physical advantages, plant-based lubricants hold great potential for rural economic development. Farmers could benefit not only from increased demand for vegetable oils but also, and more significantly, from collective ownership of a company manufacturing value-added products.

Along with the advantages, there have traditionally been a number of technical concerns with the performance of vegetable oil-based lubricants. The two main issues are operational temperature limitations and oxidative instability. In cold weather, vegetable oils have the tendency to solidify more readily than petroleum products, giving them a higher pour point (the temperature at which the lubricant can still be poured). In conditions of extreme heat, they are subject to oxidation, a 
chemical reaction that causes the oil to break down and reduces its functioning capacity.

In addressing these concerns, researchers have developed a number of plantbased lubricants that meet or exceed the performance expectations of petroleum lubricants. Current approaches include reformulating additives, chemically modifying vegetable oil and genetically modifying the oilseed crop. Very high oleic oils seem to offer the best compromise in terms of technical characteristics. As a result high oleic sunflower oil and high oleic rapeseed oil are beginning to find uses where high oxidative stability is required.

The prices of bio-lubricants are between 1.5 to 5 times higher than those for conventional lubricants. However, an appropriate political framework could promote the use of RRM and thereby allow the forecast growth in the bio-lubricant market to be realized (Table 1). Alternatively, direct financial support could provide a temporary bridge between the costs of bio- and conventional lubricants. Such a market introduction incentive is now (2002) being used to encourage the use of biodegradable lubricants in Germany (10 million Euros per year). This includes assistance with the cost of converting equipment and the increased cost of 'factory fill', i.e., the supply of new equipment already filled with biodegradable lubricants.

\section{Plant-Based Lubricants: The Future}

Though the plant-based lubricant industry is young it has made much progress in the last five years.

Ideally, manufacturers, policymakers and others involved in building the market for plant-based lubricants should encourage the involvement of farmers. As farmer ownership of lubricant manufacturing grows, rural communities will reap the benefits that plant-based lubricants offer.

Table 6: Biolubricants in Europe 2000.

\begin{tabular}{lccccc}
\hline $\begin{array}{l}\text { Lubricats market } \\
\text { sector }\end{array}$ & $\begin{array}{c}\text { Total EU } \\
\text { market }\end{array}$ & $\begin{array}{c}\text { Current EU } \\
\text { Bio-Market }\end{array}$ & $\begin{array}{c}\text { Without } \\
\text { futher } \\
\text { regulations }\end{array}$ & $\begin{array}{c}\text { Bio-market } \\
\text { by 2010 with } \\
\text { ongoing } \\
\text { legislation }\end{array}$ & $\begin{array}{c}\text { Bio-market } \\
\text { share by 2010 } \\
\text { with ongoing } \\
\text { legislation }\end{array}$ \\
\cline { 2 - 6 } & in 000 tonnes & in 000 tonnes & in 000 tonnes & in 000 tonnes & $\%$ \\
\hline Hydraulic fluids & 750 & 51 & 100 & 250 & 33 \\
Greases & 136 & 1 & 2 & 69 & 50 \\
Chainsaw lubricants & 40 & 29 & 30 & 38 & 96 \\
Mould release agents & 82 & 10.5 & 20 & 41 & 50 \\
Motor and gear oils & 2408 & 4.5 & 20 & 482 & 20 \\
Metal working fluids & 338 & 4.5 & 20 & 170 & 50 \\
Other applications & 486 & 0.5 & 10 & 240 & 50 \\
\hline Total & 4242 & 101 & 202 & 1290 & 30 \\
\hline
\end{tabular}

Legislation concerning the control of waste oil disposal and oil recycling, as well as that concerning total loss lubricants, will determine the speed with which bio- 
lubricants substitute mineral oil products. To realize the optimistic pan-European forecast, EU legislation will be essential. It is necessary to create a "critical mass" of bio-lubricants in the market that will then develop a momentum of its own. This requires, for example, to kindle the interest of equipment manufacturers in adapting their machines to the special demands of bio-lubricants. It is assumed that this momentum would be developed at a market share for bio-lubricants of approximately $20 \%$. Current EU market figures are based on Frost \& Sullivan Report 'Biolubricants in Europe 2000' which relate to 1999 volumes.

The potential European market for vegetable oil-based lubricants in 2010 is estimated to be $35 \%$ of the total lubricants market. Vegetable oil-based lubricants are considered to be one of the largest and fastest growing industrial use markets. Vegetable-based lubricants currently account for 100,000 tons of production but are expected to rise dramatically to 1.7 million tons by 2010 .

Table 7: Potential European market for biodegradable lubricants

\begin{tabular}{lccccc}
\hline & Lubricants & $\begin{array}{c}\text { Market } \\
\text { in 2000 }\end{array}$ & $\begin{array}{c}\text { Market } \\
\text { in 2010 }\end{array}$ & $\begin{array}{c}\text { Share \% } \\
\text { by 2010 }\end{array}$ & Market \\
\cline { 2 - 6 } & in 000 tonnes & in 000 tonnes & in 000 tonnes & in 000 tonnes & $\%$ \\
\hline Hydraulic fluids & 750 & 34 & 250 & 33 & 890 \\
Greases & 400 & 1 & 180 & 45 & 320 \\
Chains bar lubricants & 125 & 11 & 120 & 96 & 210 \\
Mould release agents & 225 & 4 & 180 & 80 & 320 \\
Motor and gear oils & 2,400 & 48 & 480 & 20 & 1,730 \\
Metal working fluids & 1,000 & 2 & 500 & 50 & 870 \\
\hline Total & 4,900 & 100 & 1,710 & 35 & 4,340 \\
\hline Source: Reported in realizing the economic potential of UK-Grown industrial Crop Annex-Key Statistics
\end{tabular}

In the European Community in 2010 the percentage of bio-lubricants will satisfy approximately $35 \%$ of the total lubricants market, correspondent to 1.7 million tons and 4.34 billion pounds or 6.4 billion Euros.

\section{Surfactants and Emulsifiers}

Surfactants can be categorized as anionics (negatively charged), cationics (positively charged), non-ionics (no charge) and amphoterics (containing both a positive and a negative group). Anionics and non-ionics represent the largest groups of surfactants (Falbe, 1987).

Surfactants are used in a wide range of fields, but the most important field of application is the washing and cleaning sector as well as textile treatment and cosmetics; these use more than $50 \%$ of the total amount of surfactants. Surfactants are also used in the food sector, in crop protection, mining and the production of paints, dyes and paper. Apart from soap, the most important surfactant from the amount produced is still the petrochemical-based alkyl benzene sulfonate. However, in recent years a continuous trend towards surfactants based on renewable 
resources has become apparent. The total worldwide market amounts to 10.7 million tons for the year 2000, coming from 9.2 million tons in 1995.

Surfactants constitute an important group of chemical products not only in terms of quantity (Table 1) but also in view of the great variety of applications in households, industry and agriculture. End users encounter surfactants in detergents, cosmetics and food. In manufacturing processes, surfactants are used as anti-static agents, lubricants and leveling agents (e.g., for textile production), deinking of recycled paper and as emulsifiers (in the food industry and for the production of colorants, coatings and plastics). The secondary effects produced by the introduction of more sophisticated, high-performance products can also help reduce greenhouse gas emissions. For example, the new generation of detergents washes effectively at much lower temperatures, resulting in significant energy savings.

Surfactants can be derived from both petrochemical feedstock and renewable resources (plant and animal oils). They represent a particularly interesting product group since they were originally made from renewable resources whereas today, the majority is of petrochemical origin. Still, renewable raw materials play an important role in this market since they account for about one third of the total organic carbon fixed in surfactants, with two thirds of the organic carbon being of fossil origin.

Nearly all renewable raw materials currently used for surfactant production in Europe are tropical vegetable oils, imported in Europe due to their more suitable chemical structure than oils produced from European crops such as sunflower and oilseed rape.

High oleic sunflower oil could be used in surfactants production.

\section{Herbicide-Surfactant Combinations}

Figure 17 gives examples of a few commonly used herbicides and an appropriate surfactant for use with herbicides based both on oil and water solubility. Because herbicides and surfactants differ in solubility, it is important to match the solubility of each in order to maximize their performance as a combination.

Herbicides in the hydrophilic-lipophilic balance (HLB) range from 1 to 10 are more soluble in oil than in water. Those in the HLB range from 10 to 20 are more soluble in water than in oil. Likewise, surfactants in the HLB range from 1 to 10 generally work best with an oil-soluble herbicide, and those in the HLB range from 10 to 20 generally work best with a water-soluble one.

Esterified seed oils are produced by reacting fatty acids from seed oils (corn, soybean, sunflower, canola) with an alcohol to form esters. The methyl or ethyl esters produced by this reaction are combined with surfactants/emulsifiers to form 
an esterified seed oil. These surfactants reduce surface tension and improve herbicide uptake by improving herbicide distribution on the leaf surface.

\begin{tabular}{|c|c|c|c|}
\hline & \multicolumn{2}{|c|}{ herbicides } & \\
\hline & $\begin{array}{l}\text { Posat }^{\mathrm{TM}} \\
\text { Atrazine }^{\mathrm{TM}} \quad \text { Beacon }^{\mathrm{TM}} \\
\text { Accent }^{\mathrm{TM}} \\
\quad \text { Select }^{\mathrm{TM}}\end{array}$ & $\begin{array}{c}\text { Blazer }^{\mathrm{TM}} \text { Banval }^{\mathrm{TM}} \\
\text { Pursuits } \\
\text { Roundup }^{\mathrm{TM}} \\
\text { Reflex }^{\mathrm{TM}} \text { Basagran }^{\mathrm{TM}}\end{array}$ & \\
\hline & $\begin{array}{l}\text { Oil Soluble } \\
\text { Crop Oil concentrate } \\
\text { Nitrogen Surfactant } \\
\text { blend } \\
\text { Esterified seed oil }\end{array}$ & $\begin{array}{l}\text { Organo- Silicone } \\
\text { Nitrogen-Surfactant } \\
\text { Blend } \\
\text { Nonionic Surfactant Water } \\
\text { soluble }\end{array}$ & \\
\hline & & & \\
\hline
\end{tabular}

Figure 17: Scheme of hydrophilic-lipophilic balance (HLB) range of herbicides and surfactants

\section{High oleic sunflower oil}

An oil (or its derivatives) with a high content of oleic acid and low PUFA offers many advantages and added value:

- for all kinds of applications: high oxidative stability, reduced rancidity, extended shelf life, vegetable resource image ("koscher", "BSE-free");

- for nutritional purposes: no trans fatty acids (TFA), "low-cholesterine" fat (low SAFA content; like "best oil" olive oil), GMO-free;

- in processing: reduced cleaning costs, liquid - easy transportation/storage;

- in syntheses: exactly defined functionality (double bond), high product yields (less by-products).

Oleic acid is a bulk product in natural oils and in oleochemicals. Up to now, the main source of oleic acid is inexpensive beef tallow. After cleavage into fatty acids, the resulting tallow-olein is purified by fractionation processes to an oleic acid content of $60-70 \%$ (further enrichment by purification is too expensive). Since the BSE disease and publicly discussed problems of fat recycling, a growing demand for vegetable oleic sources can be observed. These sources exist for a long time, but they are frequently limited in amount, like olive oil.

In chemistry, oleic acid is an industrial bulk product: in German oleochemistry the annual consumption of natural oils and fats is about one million tons, containing more than 200,000 t of oleic acid in absolute weight. But only a small part, approximately $20 \%$, is used in applications where the dominating high content of oleic acid is desired (in most of these applications tallow olein is used as oleic acid resource). About 15,000 to 20,000 t of HOSO are actually used for oleochemicals in Europe - far below its supposed maximum potential. 


\section{Applications}

During the last decade, research and development revealed numerous application fields for HO oils - in principle they can be described as:

- non food: mainly substitution of conventional oleic acid sources (tallow, palm) by high oleic oils

- food: substitution of partially hydrogenated or "lower oleic" oils (soy, canola, palm); substitution/blending of olive oil.

Table 8: Overview of HOSO Applications

\begin{tabular}{lcc}
\hline Suitable as (triglyceride or fatty acid derivative) & Type 89 & Type 90 \\
\hline Lubricant/hydraulic fluid (basic) & ++ & ++ \\
Metal working/cutting oils & + & ++ \\
Processing aid (production of plastics, metals) & + & ++ \\
Intermediate for chemical syntheses & + & ++ \\
Monomer (plastics,coatings) & + & ++ \\
Cometics (component) & ++ & + \\
Tenside/surfactants (component) & ++ & ++ \\
Cleaning agens/solvents & ++ & ++ \\
Deepfat frying /frying oil & $+(+)$ & ++ \\
Salad oil & ++ & ++ \\
Dieary & ++ & + \\
\hline
\end{tabular}

A fast growing usage of high-oleic sunflower oils (HOSO) can be expected, especially in cosmetics and lubricants. The lubricant sector is huge in amount: in EU approximately 5 million tons (Germany 1.1 million t) of lubricants are consumed each year. Up to now, more or less refined mineral oils strongly dominate, only $2 \%$ (Germany $4 \%$ ) of oil consumption are of vegetable oil origin. But consumption is growing pretty fast: compared to mineral oils, triglyceride or derived synthetic esters are superior in wear-reducing properties - they are the better performing lubricants. Besides technical aspects as driving forces, also the regulatory framework in the EU is more and more favoring the environmental friendly, readily biodegradable natural oils, for example in loss lubrication applications. Due to their high oxidative stability, HOSO are often favorably compared with other natural oils as base oils or additives in lubricants. Compared with mineral oil-based lubricants, bio-lubricants still face disadvantages in product costs. But cost competitiveness can be achieved in considering total costs: depending from the application, total costs nevertheless can be even lower, because of their excellent performance: reduced oil consumption, low maintenance costs (machines, tools), high product quality, less professional diseases. Great perspective awaits extreme-high oleic oils: they perform like synthetic esters (e.g., TMP-trioleates), but are rather lower in price. The future utilization of synthetic esters in lubricants is predicted to be strongly increasing (e.g., in the 2000 market study from Frost \& Sullivan), the growth can already be observed today. 


\section{Future Perspectives}

The perspectives of high oleic sunflower oils in food and non food applications are promising: a reasonable cost-performance relationship and an improving HOSO availability will drive further industrial utilization. Substitution of "lower oleic" sources, mainly of tallow, will occur, when high performance is demanded: disadvantageous properties like TFA content, bad smell, yellow color, low stability could be avoided when using high oleic oils.

Multi-step syntheses in chemistry need pure starting materials, a big drawback of oleochemicals compared with petrochemicals. For example, a 3-step synthesis, where every step is done with $70 \%$ yield, ends up with a total yield of only $34 \%$ of desired endproduct which is not economically feasible in most cases. If that is done on a $90 \%$ level, the total yield is much better - $73 \%$. With high oleic oils exceeding the $90 \%$ level of oleic acid, a new innovative oleochemistry can be developed, using the doublebond functionality as reactive center in multi-step syntheses to "high-end" products, like engineering plastics from oleic acid (via ozonolyses).

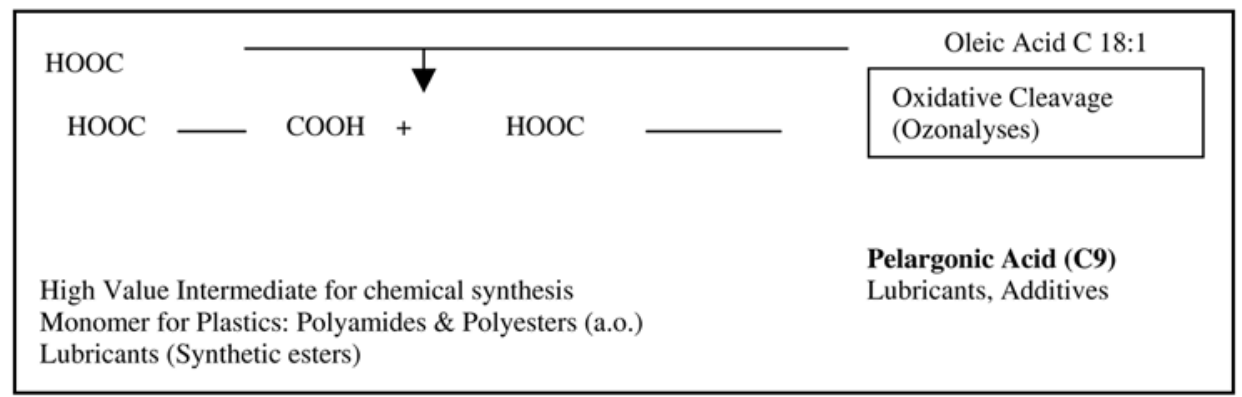

Figure 18: Scheme of oleochemicals compared with petrochemicals

Azelaic and pelargonic acids are intermediate chemicals used principally in the industrial production of polymers. At present, these acids are produced only by American firms, using a prohibitively expensive procedure. For the most part, these acids are obtained from petrochemicals. Previous laboratory studies have developed a reaction for the oxidative blending of oleic acid obtained from oleic sunflower oil that yields azelaic acid and pelargonic acid simultaneously. It would be useful to industrialize this synthesis, given its economic and environmental advantages.

The current market volume for azelaic acid is $11,700 \mathrm{t} / \mathrm{yr}$ in the United States, $800 \mathrm{t} / \mathrm{yr}$ in Europe and $900 \mathrm{t} / \mathrm{yr}$ in Japan. This market is growing at a pace of 5 to $6 \%$ yearly. Targeted applications for pelargonic acid are whitening agents and raw materials for neopolyon esters (lubricants designed for difficult conditions, plastifiers and alkyl resins). The current market volume for pelargonic acid is 27,700 t/yr, two-thirds of which are derived from petrochemicals.

The project AGRICE 9501070 has confirmed the feasibility of a three-stage process: breaking the double bond, branching the $\mathrm{OH}$ molecules then cutting again 
to obtain two acids. Oleic sunflower is the feedstock of choice, for its availability in France, good yields and the purity achieved. Investment costs are lowered by a factor of 2.5 compared to the conventional process currently used to produce these acids. Because of a technical problem that remains to be solved, an industrial production unit could not be built. The programme has now shifted its focus to hydroxylation.

The production of these acids from the high oleic sunflower will demand the cultivation of 850.000 hectares.

The increase of the production of biodiesel can favour the creation of new opportunities of job in the rural areas. Studies carry out in South Africa demonstrate that biodiesel originates 1 workplace every 10 hectares cultivates with sunflower; 2 workplaces every 10 hectares cultivate with sunflower for the oleochemistry.

\section{Barriers to Progress}

There is a clear need to set up new supply chains to enable RRM-based products to find the most effective route to market. However, there are many barriers to progress:

- It is essential to reassure industry of a consistent and reliable supply of appropriate quality raw materials.

- Financial assistance will be needed for industry to enable it to adapt to the use of these new raw materials.

- It may be necessary to reduce raw material or processing costs for the end product to be competitive in the market place.

- There is a need to adapt existing regulations to accommodate the special characteristics of RRM.

- Further development of 'designer' oil profiles is likely to be the fastest way to meet industry's needs.

- Specific 'designer' oils are coming on stream from classical selection and/or breeding programmes. These include sunflower and rapeseed varieties with very high oleic acid (C18:1) content.

- Plant breeding is required to improve crops. However, significant changes can hardly be expected in the mid-term perspective.

- Price is a major barrier to development. European oilseed prices are not competitive in comparison with the world market prices for many vegetable and mineral oils.

- This still remains true and is perhaps the most significant constraint in the development of this industry. The bio-lubricants are more expensive than mineral oils, despite their many advantages. 


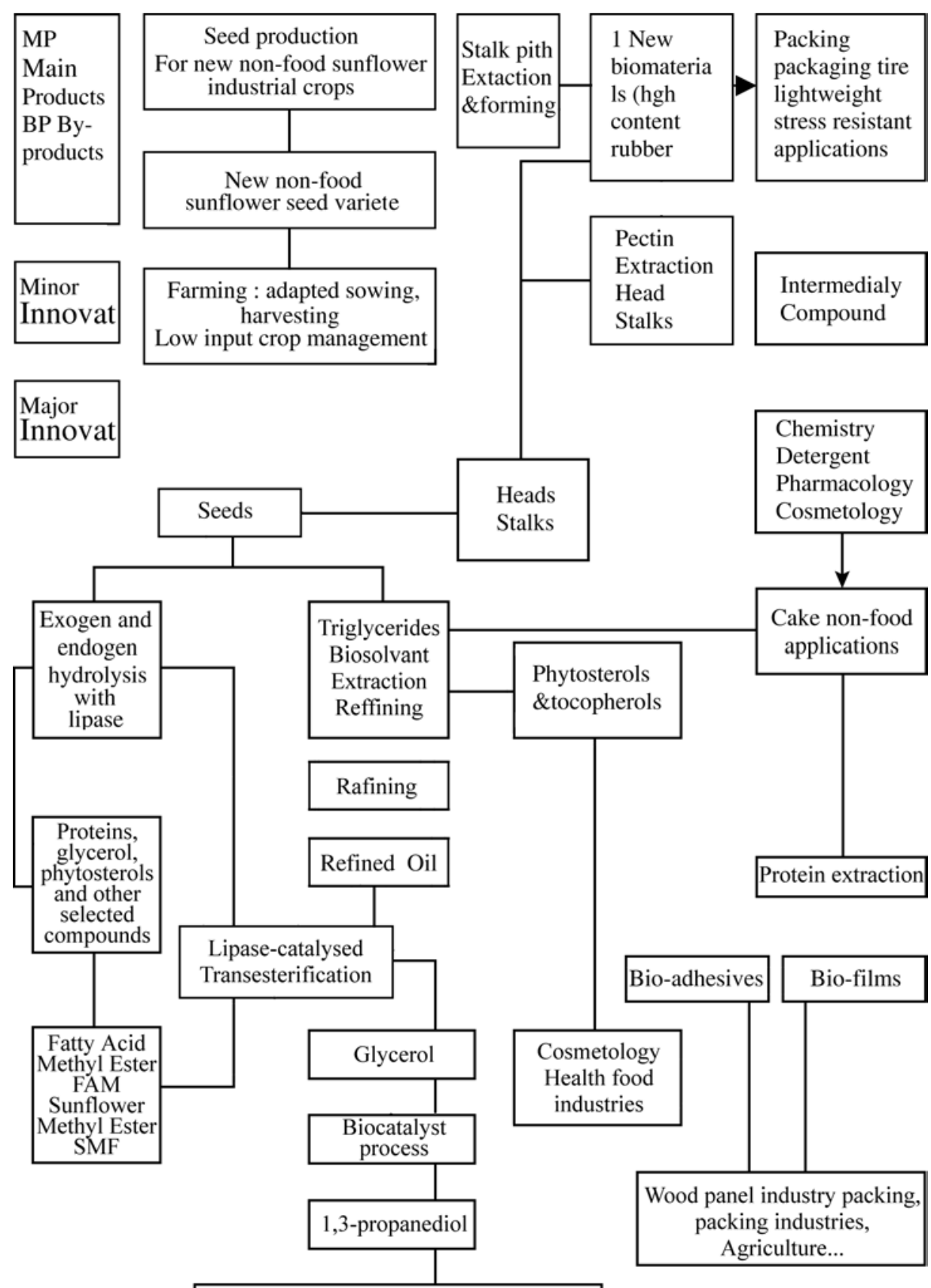

New polyesters, polyethers, polyurethane

Figure 19:The scheme of my vision for the future sunflower oil industrial use 


\section{REFERENCES}

Charlemagne, D., 1999. Huiles végétales et protection des cultures. Bio futur, 32-34

Charlemagne, D., 1999. Apport de la lipochimie à l'industrie phytosanitarie.OCL 6(5): 401-403 Dufaure, C., Mouloungui, Z.,Rigal, L., 2000. Tournesoleate 2: preparation des mileux reactionnels de graisses lubrifiantes a base d'huile de tournesol oleique additionne in situ d'oleate d'alkyle et d'oleate metallique. $15^{\text {th }}$ Int.Sunf.Conf. 12-15 June ToulouseFrance. Tome I, B-31-34

Desmarescaux, P., 1999. Place de la lipochimie dans le development des productions agricoles à usage non alimentaire. OCL 6(5): 382-383

Falbe, J. 1987. Surfactants in consumer products: theory, technology and applications, Springer, Heidelberg.

Frost \& Sullivan, U.S., 2000. Biodegradable Lubricant Markets (1999) and European Biolubricant Markets.

Gan, N.L.H., 1992. Kinetic study of epoxidation and oxirane clevage of palm olein methyl esters. J.Am. Oil. Chem. Soc. 69: 347-351

Igartua, A., "Vegetable Oils: Lifecycle of seed obtention and production, behavior during use, biodegradability and toxicity, recycling," available at http://www.dainet.de/fnr/ctvo/lubricants/Igartua.doc

Pages, X., Aflos, C., 2000. Synthesis of new derivates from vegetable sunflower oil methyl esters via epoxidation and oxirane opening. $15^{\text {th }}$ Int.Sunf.Conf. 12-15 June Toulouse- France. Tome I, B-41-47

Peelet, S., 1999. Valorisation du glycerol à travers l'étude de la reactivité chimique du carbonate du glycerol: nouvelles voies de synthèse des esters de carbonate de glycerol et propriétés. Thése I.N.P. Toulouse, Spécialité Sciences de Agroressources.

Rohers, I., Robrucker, T., 1995. Performance and ecology. Two aspects of modern greases. NLGI Spokesman, 58(12): 8-47.

Sylvain, C., 1999. Oleochemistry as an opportunity to consolidate the sustainable development of European oil crops-an updated prospect. OCL 6(5): 418-425

Van Donkelaar, P., 1990. Environmental effects of crankase and mixed lubrificants. Sci Total Environ 92: 165-169.

\section{PERSPECTIVAS EN LA UTILIZACIÓN DE GIRASOL DE ALTO CONTENIDO OLEICO EN LA INDUSTRIA DE PROCESAMIENTO Y COMO MATERIA PRIMA PARA LA PRODUCCIÓN DE ENERGÍA}

RESUMEN

El girasol con el alto contenido oleico tiene grandes potenciales para el uso industrial (industria de aceite y biodiesel). El desarrollo sostenible de la agricultura, puede lograrse por medio de la producción de girasol de alto contenido oleico, para el uso en la industria química, que guarda el medio ambiente ('green chemistry'). De esta manera se van a crear los puestos de trabajo seguros en la agricultura, tanto como en las nuevas ramas industriales, sobre todo en las creadas en las zonas rurales. 
PERSPECTIVES DE L'UTILISATION DU TOURNESOL À HAUTE TENEUR OLÉIQUE DANS L'INDUSTRIE DE TRANSFORMATION ET COMME BASE DE PRODUCTION D'ÉNERGIE

\author{
RÉSUMÉ
}

Le tournesol à haute teneur oléique représente un grand potentiel pour les besoins de l'industrie (oléochimie et biodiesel). Le développement durable de l'agriculture peut être réalisé par la production d'huile de tournesol à haute teneur oléique destinée à la «chimie verte». De cette façon, il sera possible de créer des emplois sûrs en agriculture aussi bien que dans les nouvelles industries, particulièrement dans les communautés rurales. 